\title{
Comparison of Rain Effects on Splash Dispersal of Three Colletotrichum Species Infecting Strawberry
}

\author{
N. Ntahimpera, L. L. Wilson, M. A. Ellis, and L. V. Madden
}

Department of Plant Pathology, The Ohio State University, Ohio Agricultural Research and Development Center, Wooster 44691. Current address of N. Ntahimpera: Department of Horticulture, Pennsylvania State University, University Park 16802. Accepted for publication 25 March 1999.

\begin{abstract}
Ntahimpera, N., Wilson, L. L., Ellis, M. A., and Madden, L. V. 1999. Comparison of rain effects on splash dispersal of three Colletotrichum species infecting strawberry. Phytopathology 89:555-563.

Rain simulation studies were performed to compare splash dispersal of three Colletotrichum species: $C$. acutatum $(C$. acutatum-O isolate from Ohio and C. acutatum-M isolate from Mississippi), C. fragariae (isolate from Mississippi), and C. gloeosporioides (isolate from Florida). Conidial dispersal was assessed by counting colonies formed from spore-bearing splash droplets deposited in sheltered petri plates containing a selective medium. Colonies were converted to number of conidia based on germination rates of spores on the media. The interpolated total number of dispersed conidia over a $61 \mathrm{~min}$ rain and $72 \mathrm{~cm}$ from the point source $(\Sigma)$ was calculated. For all species, a rain intensity of $30-\mathrm{mm} / \mathrm{h}$ resulted in significantly greater dispersal than an intensity of $11-\mathrm{mm} / \mathrm{h}$. C. fragariae had the lowest amount of spore dispersal, and $C$. acutatum-O had the highest dispersal. C. acutatum-M and C. gloeosporioides were intermediate in
\end{abstract}

ABSTRACT magnitude of conidial splash dispersal. However, differences were directly attributed to differences in spore density per fruit at the source. When $\Sigma$ was corrected for source strength $\left(\Sigma_{r}\right)$, the species were very similar, with only $C$. acutatum-M having a mean $\Sigma_{r}$ significantly less than the others. Proportions and rates of spore removal (per minute) from source fruits were higher for $C$. acutatum-O and $C$. gloeosporioides than for other isolates. Wash-off rates of conidia deposited on healthy fruits were the same for all species. Deposition flux density of spores that had been uniformly sprayed over the entire soil surface of the experimental area was affected by species. A significant difference in means was observed between $C$. acutatum and C. fragariae - the latter had a somewhat lower flux density. This is the first demonstration that closely related species infecting the same plant species are similar in terms of splash dispersal.

Additional keywords: anthracnose, disease spread, Fragaria $\times$ ananassa, mechanistic model, quantitative epidemiology.
Anthracnose diseases have become a major constraint in strawberry (Fragaria $\times$ ananassa) production in the United States and other countries $(7,17,37)$. All plant parts can become infected, resulting in substantial yield losses. Anthracnose is caused by $\mathrm{Col}$ letotrichum acutatum J.H. Simmonds, C. gloeosporioides (Penz.) Penz. \& Sacc. in Penz. (teleomorph Glomerella cingulata (Stonem.) Spauld. \& Schrenk), and C. fragariae Brooks $(2,16,17)$. C. dematium (Pers.) Grove also can occasionally cause strawberry fruit rot (17). The first three species have similar spore dimensions, but their germination rates on selective media, infection efficiencies on fruits, and spore production rates on diseased fruits are species dependent $(19,39,40)$.

Within the last few years, $C$. acutatum has become the dominant species infecting strawberry fruits in many parts of the United States $(7,46)$. Often, $C$. gloeosporioides and $C$. fragariae are associated with plant parts other than fruit, but both are capable of infecting and rotting strawberry fruits (17). Although there has been considerable controversy surrounding the taxonomy of the genus $(15,37)$, recent isozyme and molecular evidence has confirmed the uniqueness of the three Colletotrichum species $(3,20,36)$. In fact, the grouping of Colletotrichum isolates based on arbitrarily primed polymerase chain reaction, A+T-rich DNA, and nuclear DNA analyses correspond to the grouping formed based on classical taxonomic identification (13). Classical identification was based on morphological characterizations of conidia, vegetative and sexual structures, cultural characteristics, and host specificity $(8,15,37)$.

Corresponding author: L. V. Madden; E-mail address: madden.1@ osu.edu

Publication no. P-1999-0426-02R

(C) 1999 The American Phytopathological Society
Species in the Colletotrichum genus are characterized by rainsplash dispersal of conidia produced in acervuli $(11,22)$. Any splashdispersal process generally includes detachment of pathogens by impaction of water drops and transport of spore-bearing splash droplets to new locations $(1,18,21,43)$. Previously, we studied dispersal at three hierarchical levels: splash of single-incident drops onto an inoculum source, dispersal of $C$. acutatum spores over distances with simulated rains that mimicked natural rains, and development of strawberry disease epidemics in fields with variable intensities, durations, and timings of rains $(4,22,24,25,43)$.

There has been general interest in comparative approaches to splash-dispersal research since the pioneering work of Stepanov (38) and Gregory et al. (14) to gain a better understanding of the mechanisms involved in spore dissemination. These researchers released a stream of large water drops onto cultures or spore suspensions of several fungal species and determined various aspects of splash-droplet production and spore entrainment in splash droplets. For the most part, these valuable investigations used unrelated or marginally related species and did not study dispersal from infected plant units. For instance, Gregory et al. (14) worked on Gloeosporium album, C. lindemuthianum, Nectria cinnabarina, and Fusarium solani. More recently, Fitt et al. (12) emphasized the value of comparative studies in understanding splash dispersal. Splash dispersal has been compared in detail between two or more pathogens that differed in spore shape and size, such as Pseudocercosporella herpotrichoides and Pyrenopeziza brassicae in one study (9) and C. acutatum and Phytophthora cactorum in others (26, 44).

Using a rain simulator, propagules of $C$. acutatum and Phytophthora cactorum, cause of leather rot, were dispersed effectively under a range of rain intensity and ground cover conditions (26, $27,35,45,46)$, and the presence of a cover crop over a surface (29) 
or increasing strawberry plant density reduced splash dispersal (4). Single water-drop impactions on infected fruits also were used to quantify splash-droplet production and movement in relation to properties of impacting water drops (43). Various properties of water drops, such as drop size, velocity, and kinetic energy, were related to splash response, spore entrainment, and droplet flight distributions $(22,30,43,44)$. Considerable differences existed in the splash-dispersal process between $C$. acutatum and Phytophthora cactorum $(26,44)$. Although disease incidence increased with rain duration for both pathogens, a higher proportion of infected strawberry fruits was observed with $C$. acutatum than with Phytophthora cactorum (26). However, the differences in dispersal were partially attributable to the higher inoculum density of $C$. acutatum on strawberry fruit compared with Phytophthora cactorum. Fatemi and Fitt (9) found that splash-dispersal characteristics, such as pattern of spore dispersal, spore-carrying droplet distribution, and number of spores within droplet-size categories of Pseudocercosporella herpotrichoides and Pyrenopeziza brassicae, were similar. There is no information on genetic determinants of splash dispersal for these or any other fungal species.

The objective of our study was to characterize how splash dispersal of three different, but closely related, Colletotrichum species that infect strawberry fruit is affected by rainfall. Because spore removal and transport are essentially physical processes, it was hypothesized that rain intensity would have the same effect on all species. Results should provide guidance as to what extent one can extrapolate splash-dispersal findings from one fungal species to another. Furthermore, the results may contribute to our understanding of the reason why $C$. acutatum has become a dominant anthracnose-causing pathogen of strawberry in the United States. Preliminary results were reported previously (31).

\section{MATERIALS AND METHODS}

Rain generation system. The rain simulator developed at The Ohio State University, Ohio Agricultural Research and Development Center (35), was used to investigate the effect of rainfall on splash dispersal of different Colletotrichum species. The system consisted of an upward-pointing and rotating wide-angle spray nozzle (Spraying Systems, Inc., Wheaton, IL) that produced a conical pattern and ensured generation of uniform rain at the ground surface over a $1.2 \times 1.2-\mathrm{m}$ area. Two different wide-angle spray nozzles, $20 \mathrm{~W}$ and $35 \mathrm{~W}$, were used individually at $69-\mathrm{kPa}$ water pressure to generate simulated rains of $\approx 11$ and $30 \mathrm{~mm} / \mathrm{h}$, respectively (27). The height of drop fall was $\approx 4 \mathrm{~m}$, which resulted in the largest drops $(\approx 4 \mathrm{~mm}$ in diameter) reaching $85 \%$ of terminal velocity.

Source of isolates and inoculum production. Two isolates of C. acutatum were used, one from Ohio (C. acutatum-O, ATCC 90170) and one from Mississippi (C. acutatum-M, Mil-1). An isolate of C. gloeosporioides from Florida (CG-162) and C. fragariae from Mississippi (MS-9) also were tested. Only C. acutatum has been found in Ohio. Dr. B. J. Smith, (U.S. Department of Agriculture, Agriculture Research Service, Poplarville, MS) supplied the other isolates. To maintain fungal pathogenicity, fruits were inoculated regularly with the isolates, and the fungi were reisolated from infected fruits following methods previously described $(39,46)$. Conidia were scraped from infected fruits and streaked on potato dextrose agar (PDA), and cultures were incubated in the dark at $25^{\circ} \mathrm{C}$ for up to 7 days. Spore suspensions for fruit inoculation were prepared by scraping conidia from culture plates, suspending them in deionized water, and adjusting the density to $10^{5}$ conidia per $\mathrm{ml}$ with the aid of a hemacytometer.

Detached, immature (green-to-white stage) fruits from greenhousegrown plants were washed with deionized water, surface-sterilized in $70 \%$ ethanol for $60 \mathrm{~s}$, rinsed with deionized water, dried, and placed on elevated screens (6-mm mesh) in 5-liter plastic containers. The containers were filled with $\approx 700 \mathrm{ml}$ of deionized water. The pedicel of each fruit was inserted through the mesh of the metal screen and immersed in water to minimize fruit desiccation. Fruits were sprayed to runoff with a conidial suspension. Containers were closed and incubated at $25^{\circ} \mathrm{C}$ for $24 \mathrm{~h}$ to ensure infection (39), after which lids were removed and fruits were kept at $25^{\circ} \mathrm{C}$ for 7 days to ensure lesion development and sporulation. This regime resulted in fruits covered by lesions.

Spore germination. Germination rates of spores from the four isolates were determined on a semiselective medium for Colletotrichum developed by Eastburn and Gubler (7). The medium is a modified dextrose-peptone-yeast extract agar (32) containing benomyl at $5 \mathrm{mg}$ a.i./liter but without $\mathrm{FeCl}_{3} \cdot 6 \mathrm{H}_{2} \mathrm{O}$. Suspensions containing 75, 150,750, 1,500, and 3,000 conidia per ml were prepared for each isolate, and a $0.2-\mathrm{ml}$ drop from each suspension was streaked on petri plates containing selective medium. These concentrations resulted in 15, 30, 150, 300, and 600 spores per plate; five plates were used for each concentration. Plates were incubated at $25^{\circ} \mathrm{C}$ under continual fluorescent light for $48 \mathrm{~h}$, after which colonies were counted. Control plates consisted of uninoculated plates incubated under similar conditions.

Sheltered gravity samplers and spore deposition. A wood frame $(1.5 \times 1.5 \mathrm{~m})$ was placed immediately below the rain generator. The frame was covered with sterilized standard soil mix to a depth of $\approx 3 \mathrm{~cm}$. The mix was made up of soil and peat moss $(5: 1, \mathrm{vol} / \mathrm{vol})$, supplemented with $150 \mathrm{~g}$ of $9-45-15 \mathrm{~N}-\mathrm{P}_{2} \mathrm{O}_{5}-\mathrm{K}_{2} \mathrm{O}$ fertilizer and lime. New soil mix was used for each test run. To determine splash dispersal, five strawberry fruits with sporulating lesions (inoculated with one isolate 7 days earlier) were clustered on the ground 30 to $40 \mathrm{~cm}$ from one corner of the frame. Petri plates $(6 \mathrm{~cm}$ in diameter) containing selective medium for Colletotrichum (7) were positioned, with the lids removed, under rainshields at 12, 27, 42, 57 , and $72 \mathrm{~cm}$ (one plate for each distance) from the inoculum source, as described by Madden (22) and Yang et al. (45). To test for contamination of ground cover, one plate was placed under a rainshield and exposed to $1 \mathrm{~min}$ of generated rain before introducing source fruits.

Beginning at 0 min into a simulated rain, plates were exposed to splashing water every $5 \mathrm{~min}$ for 1 -min periods, for a total rain duration of $61 \mathrm{~min}$. New plates were used for each time period and distance. Exposed plates were covered with lids and incubated at $25^{\circ} \mathrm{C}$ for 2 days and then transferred to a refrigerator at $6^{\circ} \mathrm{C}$ for 2 to 3 days. For each plate, colonies corresponding to each time (rain duration) and distance from the source were counted with the aid of a magnifying plate counter (Leica Darkfield Colony Counter, Buffalo, NY). Colony numbers per unit area were converted to conidia numbers per unit area by dividing by the germination rate of the isolate. Periodically, representative colonies were transferred to PDA medium to obtain greater sporulation for examination of morphological characteristics and positive fungal identification. Tests with the two rain intensities and four isolates (three species) were repeated at least three times. Simulated rain tests were done in random order.

In an ancillary experiment to determine the effects of inoculum source strength on splash dispersal, 2, 4, 8, and 16 strawberry fruits with sporulating lesions (inoculated 7 days earlier with $C$. acutatum-O or $C$. fragariae) were used for the inoculum source in rain simulations. Other conditions, such as area soil cover and positioning of petri plates over the area, were the same as in the first (standard) study. The fruits with sporulating lesions and the entire area were exposed to a rain intensity of $30-\mathrm{mm} / \mathrm{h}$, for $61 \mathrm{~min}$. Conidia were collected every $5 \mathrm{~min}$, as described above, in petri plates placed under rainshields, and the number of colonies formed in each plate was counted 5 days later. Colonies per unit area were converted to conidia per unit area based on spore germination. Simulations were done at least three times for each source strength and isolate.

Spore removal. Effects of simulated rain on conidia removal from inoculum source fruits were evaluated in a separate experi- 
ment with the rain simulator following the method described by Madden et al. (27). In brief, sterilized soil mix was placed over the wood frame, and five infected strawberry fruits with sporulating lesions were placed individually on the soil surface with at least $40 \mathrm{~cm}$ between fruits. The fruits had been inoculated 7 days earlier (as described above) with one isolate and incubated at $25^{\circ} \mathrm{C}$. The entire area received a simulated rain lasting $16 \mathrm{~min}$, at an intensity of either 11 or $30 \mathrm{~mm} / \mathrm{h}$. Exposed fruits were collected, and spore density remaining on each fruit was determined. Spore density for rain-exposed fruits $\left(D_{E}\right)$ was divided by the mean spore density for five fruits not exposed to rain (i.e., control fruits $\left[D_{C}\right]$ ) but otherwise treated the same as exposed fruits; the proportion was subtracted from 1 to obtain the proportion of spores removed by rain: $S_{R}=1-\left(D_{E} / D_{C}\right)$. The rate of spore removal was calculated by assuming an exponential decline in spore density per fruit, as was found previously (26). Rate of removal, $\beta_{R}$ (units of per minute), was given by $\beta_{R}=\left[\ln \left(D_{C}\right)-\ln \left(D_{E}\right)\right] / 16$ (27). Isolates and intensities were done in random order, and the experiment was repeated at least three times.

Spore wash-off. The removal of spores deposited on healthy strawberry fruits (i.e., wash-off) was estimated as previously described (27). Our study focused on splash dispersal of spores from potential infection sites after they were splashed from the inoculum source. Sterilized soil mix was placed on the wood frame, and 20 healthy, immature (whitish) fruits were placed individually on the soil surface, in an approximately uniform arrangement. A spore suspension ( 2 or $4 \times 10^{3}$ conidia per $\mathrm{ml}$, based on isolate infection efficiency [L. V. Madden, unpublished data]) was prepared with sterile distilled water from infected fruits incubated in the laboratory. Immediately before a simulated rain, $0.05 \mathrm{ml}$ of the spore suspension was placed on top of each fruit with a micropipette (Eppendorf Comforpette 4700, Netheler-Hinz GmbH, Hamburg, Germany; inaccuracy $=0.6 \%$ ), which resulted in an average of 100 or 200 conidia per fruit, depending on the isolate. Surface tension initially kept the water on the fruit. The entire area received a simulated rain lasting $16 \mathrm{~min}$, and fruits were collected by holding the pedicels and placed in 5-liter containers, as was done for inoculum production (described above). Twenty control fruits were inoculated with $0.05 \mathrm{ml}$ of spore suspension before each rain simulation but were not exposed to rain; these fruits were incubated as described for treated fruits.

After 7 days of incubation at $25^{\circ} \mathrm{C}$ ( 1 day with the lid on the container and 6 days with no lid), infected fruits were identified by visual symptoms. The proportion of fruits infected for rainexposed $\left(y_{E}\right)$ and control $\left(y_{C}\right)$ fruits was determined for each repetition of the experiment. The multiple-infection transformation $\left(\mathrm{MIT}_{E}=-\ln \left(1-y_{E}\right) ; \operatorname{MIT}_{C}=-1 \mathrm{n}\left(1-y_{C}\right)\right)$ was calculated to give the hypothetical number of infections per fruit (6). Following this regime, the overall average $y_{C}$ was $0.73\left(\mathrm{MIT}_{C}=1.31\right.$, indicating $\approx 1.3$ infections per fruit). Calibration studies with a range of spore densities on fruits not exposed to rain showed there was a linear relationship between MIT $_{C}$ and spore density in the range of $10^{3}$ to $10^{4}$ conidia per $\mathrm{ml}$ ( $\mathrm{L}$. V. Madden, unpublished data). This method of assessing spore numbers through transformation of infected fruits is valuable at the low densities of spores per fruit used here, when precise direct estimation of washed-off spores would be extremely difficult (27).

The number of spores removed by rain (wash-off) for any run of the rain simulator was estimated by $S_{W}=1-\left(\mathrm{MIT}_{E} / \mathrm{MIT}_{C}\right)$. Rate of wash-off ( $\beta_{W}$; units of per minute) was calculated as: $\beta_{W}=$ $\left[1 \mathrm{n}\left(\mathrm{MIT}_{C}\right)-\ln \left(\mathrm{MIT}_{E}\right)\right] / 16$. Tests were done at two rain intensities (11 and $30 \mathrm{~mm} / \mathrm{h}$ ) for each isolate. Isolates and intensities were done in random order, and the experiment was repeated at least three times.

Spore recovery. An additional study was done to compare recovery of spores of the four tested isolates from soil. This experiment focused on the splash dispersal of spores after removal from source fruits but before deposition on infection sites. The wood frame was covered with sterilized soil (as described above), and a single rain intensity $(30 \mathrm{~mm} / \mathrm{h})$ was used. A solution of $2 \times 10^{4}$ conidia per $\mathrm{ml}$ of each isolate was prepared from infected fruits with sporulating lesions (as previously described), and $900 \mathrm{ml}$ of the suspension was sprayed uniformly, using a pressurized $\mathrm{CO}_{2}$ tank, onto bare soil immediately after a 12-min simulated rain, which resulted in an average of 1,800 conidia per $\mathrm{cm}^{2}$. Spore samplers with rainshields were placed at five positions in the area. The area received $5 \mathrm{~min}$ of simulated rain. Petri plates with selective media were exposed for 1 -min periods beginning at 0,2 , and 4 min into the simulated rain period. Plates were collected and incubated as previously described, and the number of colonies obtained in each plate was counted 5 days later. Numbers of colonies per unit area were converted to numbers of conidia per unit area based on respective spore germination rates. The experiment was done from two to four times, depending on the isolate.

Data analysis. Deposition flux density of spores in petri plates ( $Y$; units of per square centimeter per minute) was determined for each distance, time (rain duration), isolate, rain intensity, and experiment repetition. Assuming equal dispersal in all directions, because of lack of air flow, the interpolated total number of conidia $(\Sigma)$ dispersed during each 61-min rain period over a circular area with a radius of $72 \mathrm{~cm}$ (the maximum distance measured) was estimated by numerical integration over both the distance and time domains (45). Integration was done following Simpson's $3 / 8$ rule with SURFER software (Golden Software, Inc., Golden, CO).

Effects of rain intensity and species or isolate on $\Sigma$ (or functions of $\Sigma$ ) were determined by analysis of variance (ANOVA). Relative number of total conidia $\left(\Sigma_{r}\right)$ was determined by dividing $\Sigma$ for each repetition by the mean inoculum density of the source for each isolate: $\Sigma_{r}=\Sigma\left(f \cdot D_{C}\right)$, where $f=5$ for the first experiment, (i.e., number of source fruits used in the experiment). For convenience, $\Sigma_{r}$ was presented as the number of conidia per 1,000 conidia at the source. Based on prior work characterizing heterogeneity of colonies per plate (23), $\Sigma$ and $\Sigma_{r}$ were transformed to $\Sigma^{1 / 5}$ and $\Sigma_{r}^{1 / 5}$, respectively, prior to ANOVA to stabilize variances and obtain approximately normal distributions. The experimental design for most experiments was a randomized complete block, with isolate and rain intensity as the main effects and experiment repetition as the block. For the source strength experiment, the main effects were number of source fruits and isolate, with repetition as the block.

Effects of rain intensity and isolate on $S_{R}, \beta_{R}, S_{W}$, and $\beta_{W}$ were determined by ANOVA. To stabilize variance, $\ln \left(S_{R}\right)$ and $\ln \left(S_{W}\right)$ were used in the ANOVA. To study spore recovery from soil, effects of isolate and time on the fifth-root of spore density $\left(Y^{1 / 5}\right)$ were assessed by ANOVA; transformation was based on prior results (23). The experiment was a repeated-measure design, with isolate as the main effect, repetition as the block, and time ( 0,2 , and $4 \mathrm{~min})$ as the repeated measure. The GLM procedure of SAS (Cary, NC) was used for ANOVA. For all experiments, means and standard errors were calculated prior to transformation for presentation purposes.

To study all four isolates (i.e., three species) and two rain intensities, the random-jump model of Pielaat et al. (33) was fitted to the data. The model can be written as

$$
Y_{t, r}=\left\{e^{-\lambda t} \cdot \delta(r)+\sum_{i=1}^{\infty}\left[\varepsilon^{i} \cdot \frac{(\lambda t)^{i} e^{-\lambda t}}{i !} \cdot \frac{e^{-\left(r^{2} / 2 i \sigma^{2}\right)}}{2 \pi i \sigma^{2}}\right]\right\} \cdot Y_{0, r}
$$

in which $Y_{t, r}$ is deposition flux density of spores at time $t$ (minutes) and distance (straight-line) from source $r$ (centimeters); $Y_{0, r}$ is initial spore density at the source; $\lambda, \sigma$, and $\varepsilon$ are parameters; $i$ is a counting index $(i=1,2, \ldots, \infty)$; and $\delta(r)$ is the Dirac delta function (by definition $\delta(r)$ is 1 at $r=0$ and 0 at $r>0$ ) (33). Theoretically, parameter $\lambda$ represents the probability per time of a spore being splashed, $\varepsilon$ represents the probability per splash event of a spore remaining in the system $(1-\varepsilon$ is the probability per splash of a spore being removed [lost]), and $\sigma$ represents the standard deviation of the distribution of distances that spores can travel during a single splash event. The diffusion splash-dispersal model 
of Yang et al. (42) is a special case of equation 1 that works well for several data sets $(27,29,30)$. Pielaat and van den Bosch (34) recently showed that use of the diffusion equation is quite restrictive under many dispersal conditions and showed the generality of equation 1.

To estimate parameters, two composite variables were calculated from the observed $Y$ data: the total number of spores dispersed over all distances at time $t\left(Y_{t}\right)$ and the mean-squared distance spores are dispersed at time $t$ multiplied by $Y_{0, r}\left(\bar{r}_{t}^{2} \cdot Y_{0, r}\right)$. As done pre-

\section{$11 \mathrm{~mm} / \mathrm{h}$}
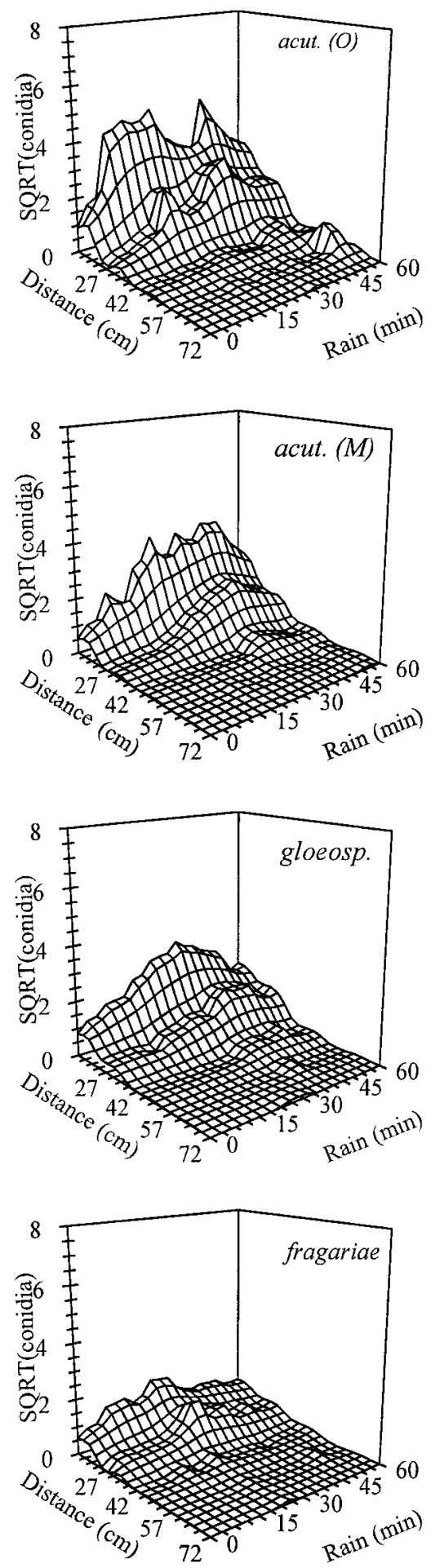

viously (33), the three parameters were estimated by fitting equations 15 and 21 of Pielaat et al. (33) simultaneously to the composite variables by nonlinear least squares. Parameters were estimated with the MODEL procedure of SAS by the SUR algorithm.

\section{RESULTS}

Initial spore density. There were significant $(P<0.001)$ differences in spore density among isolates when fruits were incubated

\section{$30 \mathrm{~mm} / \mathrm{h}$}
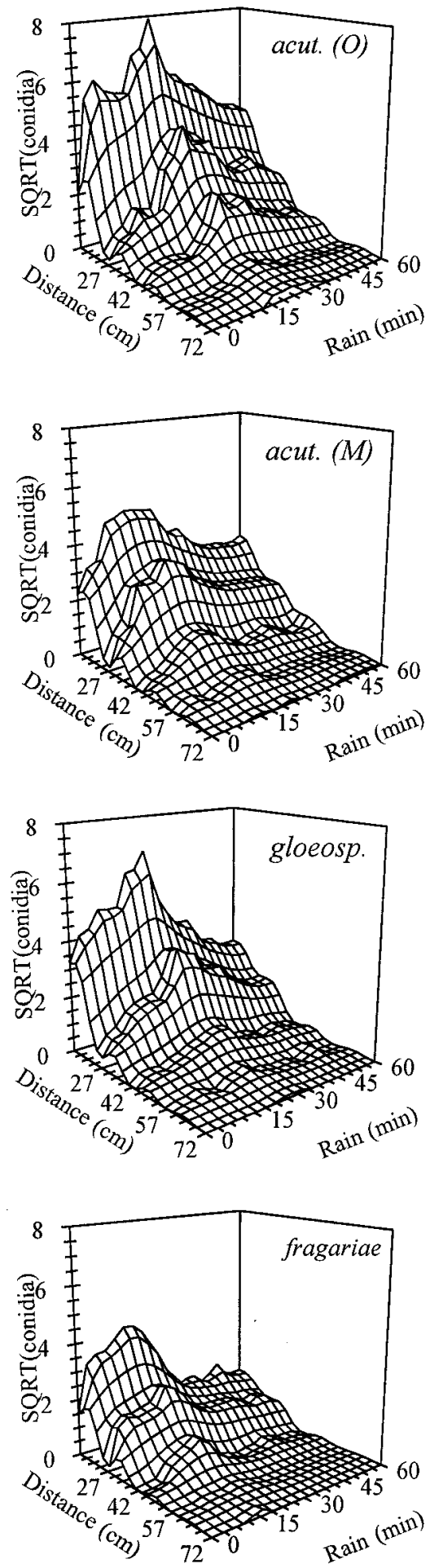

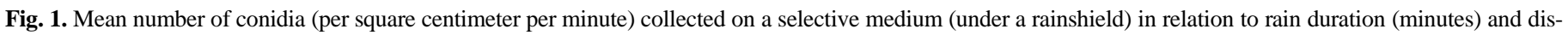

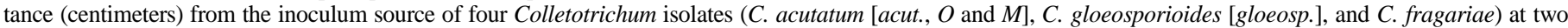
rain intensities (11 and $30 \mathrm{~mm} / \mathrm{h}$ ). Square-root of conidia (SQRT(conidia)) was used to better illustrate the data at $42 \mathrm{~cm}$ and beyond, where conidia density was low. 
under our standard laboratory conditions. The $C$. acutatum isolates (from Ohio and Mississippi) had the highest density of spores $\left(5 D_{C}\right)$, although differences in sporulation existed between the two isolates. $C$. acutatum-M lesions had approximately twice as many conidia $\left(\right.$ mean $=16.2 \times 10^{8}$; standard error $\left.[\mathrm{SE}]=0.57 \times 10^{8}\right)$ as $C$. acutatum-O lesions $\left(\right.$ mean $\left.=8.95 \times 10^{8} ; \mathrm{SE}=0.28 \times 10^{8}\right)$. The $C$. gloeosporioides isolate had an intermediate spore density (mean $=$ $4.9 \times 10^{8} ; \mathrm{SE}=0.59 \times 10^{8}$ ) that was approximately half that obtained with $C$. acutatum-O. The $C$. fragariae isolate had the lowest spore density, with a mean of $1.8 \times 10^{8}\left(\mathrm{SE}=0.27 \times 10^{8}\right)$.

Spore germination. The percentage of spore germination was calculated based on counted colonies formed in each petri plate relative to the number of conidia applied. C. acutatum-O had the lowest spore germination rate $(32 \% ; \mathrm{SE}=5.4)$. Less than half the conidia germinated for $C$. gloeosporioides (CG-162) $(41.5 \%$; $\mathrm{SE}=$ 10.3). Germination rates for $C$. fragariae (MS-9) and C. acutatum-M were $51 \%(\mathrm{SE}=12.4)$ and $77 \%(\mathrm{SE}=3.1)$, respectively.

Conidia deposition flux density. The spatial and temporal patterns of mean spore density ( $Y$, deposition flux density) with respect to rain duration and distance from inoculum source for each isolate and two rain intensities (11 and $30 \mathrm{~mm} / \mathrm{h}$ ) are illustrated in Figure 1. As with previous studies $(27,30,45)$ with $C$. acutatum, the $Y$ of all isolates generally declined with distance at any time and increased over time to a maximum and then declined. As expected, $Y$ was higher at a rain intensity of $30 \mathrm{~mm} / \mathrm{h}$ than at $11 \mathrm{~mm} / \mathrm{h}$.

The estimated total number of conidia over a 61-min rain and $72 \mathrm{~cm}$ from the source $(\Sigma)$ was highly affected by rain intensity and isolate (Table 1). There was a significant effect of intensity $(P<0.01)$ and isolate $(P<0.01)$ on the transformed total number of spores $\left(\Sigma^{1 / 5}\right)$, but block (experiment repetition) was not significant $(P>0.10)$ based on ANOVA. The lack of block effect indicates that the magnitude of $\Sigma^{1 / 5}$ did not vary with repetition of the experiment. There was no interaction between intensity and isolate $(P>0.10)$. For all isolates, there were more than two times the number of conidia collected at a rain intensity of $30 \mathrm{~mm} / \mathrm{h}$ than at $11-\mathrm{mm} / \mathrm{h}$. C. acutatum-O had the highest mean $\Sigma$ at both intensities, and $C$. fragariae had the lowest. Because the interaction between isolate and rain intensity was not significant $(P>0.10)$, means of $\Sigma$ (and $\Sigma^{1 / 5}$ ) across both rain intensities were calculated and compared (Table 1). The transformed total number of conidia of $C$. acutatum-O was significantly higher $(P<0.001)$ than the mean $\Sigma^{1 / 5}$ of the other isolates. C. acutatum-M and C. gloeosporioides had mean $\Sigma^{1 / 5}$ values that were not significantly different from each other, whereas $C$. fragariae had the lowest $\Sigma^{1 / 5}$ value.

The total number of conidia relative to initial spore density $\left(\Sigma_{r}\right)$, and its transformation $\left(\Sigma_{r}^{1 / 5}\right)$ varied with rain intensity and isolate, but not necessarily in the same manner $\Sigma$ (and $\Sigma^{1 / 5}$ ) varied with these factors (Table 1). $\Sigma_{r}^{1 / 5}$ was significantly affected by rain intensity $(P<0.01)$ and isolate $(P<0.01)$ but not by block $(P>0.10)$. Mean $\Sigma_{r}^{1 / 5}$ was higher for rain intensity at $30 \mathrm{~mm} / \mathrm{h}$ than at $11 \mathrm{~mm} / \mathrm{h}$. There was no significant interaction $(P>0.10)$ between intensity and isolate, indicating that comparisons among isolates could be based on means of $\Sigma_{r}^{1 / 5}$ across the two intensities. Mean $\Sigma_{r}$ ranged from 0.6 to 2.3 spores per 1,000 source spores at $11 \mathrm{~mm} / \mathrm{h}$ and from 1.6 to 7.3 spores per 1,000 source spores at $30 \mathrm{~mm} / \mathrm{h}$.

For data averaged across intensities, $\Sigma_{r}$ ranged from 1.1 to 4.6, and there was a high degree of similarity among most of the isolates (Table 1). Based on a comparison of $\Sigma_{r}^{1 / 5}$, C. acutatum-M had an overall mean that was slightly, but significantly, smaller than that of $C$. acutatum-O, C. fragariae, and C. gloeosporioides. The smaller mean could be attributed to the substantially larger spore density at the source for C. acutatum-M than the other isolates and intermediate mean $\Sigma$.

Source strength. There was a significant effect $(P<0.001)$ of number of infected fruits at the source on $\Sigma^{1 / 5}$, with mean $\Sigma$ (or $\Sigma^{1 / 5}$ ) increasing with fruit number (data not shown). This effect was expected, because increasing the number of source fruits increased the number of conidia available for dispersal. Isolate also had a

TABLE 1. Total number of conidia of four Colletotrichum isolates collected in petri plates containing selective medium, removal of spores from infected strawberry fruits, and wash-off of spores deposited on healthy fruits at two rain intensities ${ }^{\mathrm{w}}$

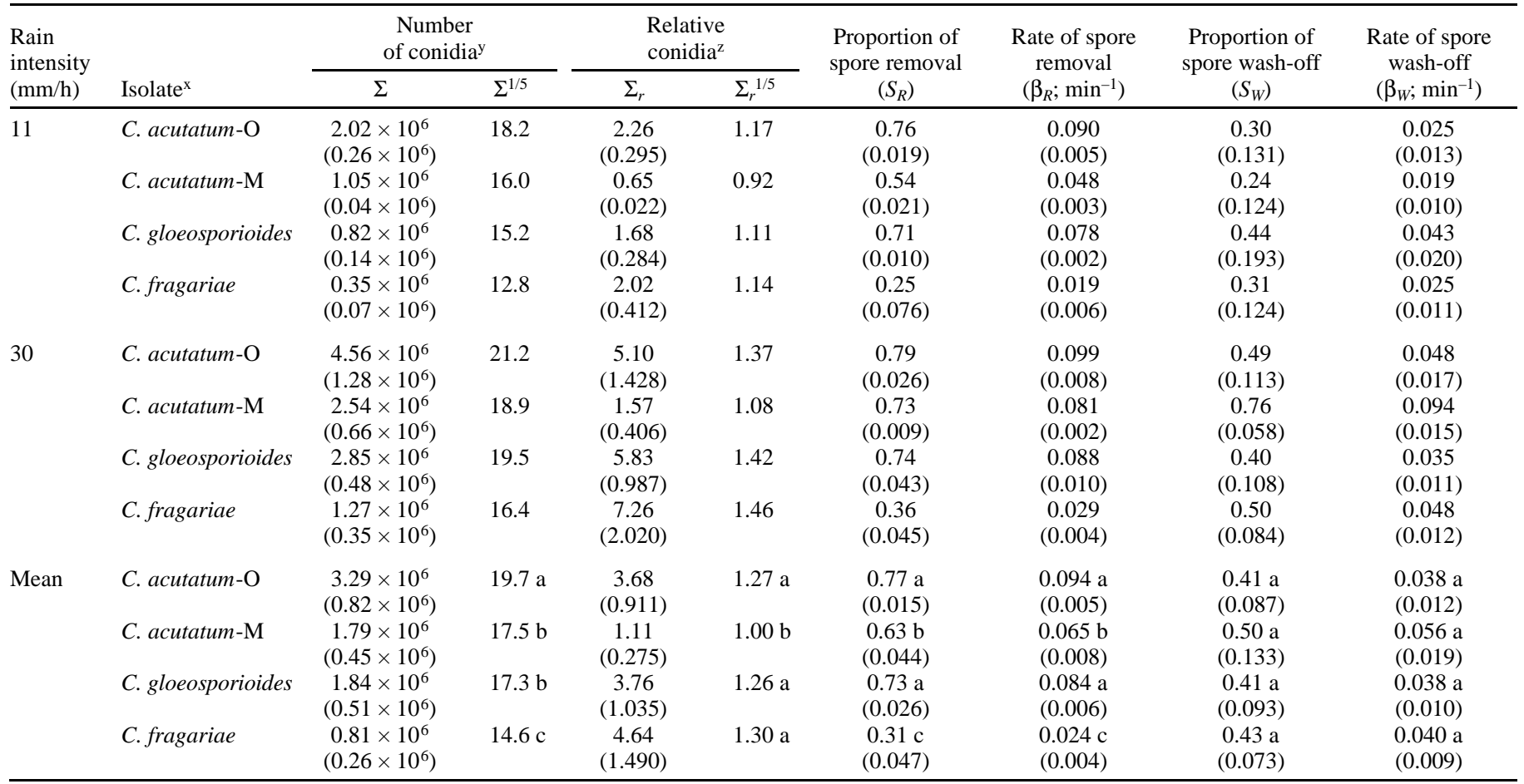

${ }^{\mathrm{w}}$ Standard errors are given in parentheses. Means followed by the same letter in a given column are not significantly different based on Fisher's protected LSD test $(P=0.05)$. Comparisons are only for the averages of means for rain intensities of 11 and $30 \mathrm{~mm} / \mathrm{h}$.

${ }^{\mathrm{x}}$ Isolate designations and origins are given in text.

${ }^{\text {y }} \Sigma$ : interpolated total number of conidia deposited over a circular area with a radius of $72 \mathrm{~cm}$ during a 61 -min rain episode; $\Sigma^{1 / 5}$ : fifth root of $\Sigma$. Results shown are means of $\Sigma$ or $\Sigma^{1 / 5}$ calculated from individual replications.

${ }^{\mathrm{z}} \Sigma_{r}: 1,000 \cdot \Sigma /\left(5 D_{C}\right)$, in which $D_{C}$ is the mean number of conidia per fruit at the inoculum point source. 
significant effect $(P<0.001)$ on $\Sigma^{1 / 5}$. However, the number of fruits did not significantly $(P>0.30)$ affect transformed $\Sigma$ relative to the number of spores at the source $\left(\sum_{r}^{1 / 5}\right)$, i.e., increasing the number of spores at the source (by increasing the number of fruits) did not increase or decrease the proportion of spores recovered during a rain. Isolate had a barely significant effect $(P=0.054)$. There were, on average, $1.3(\mathrm{SE}=0.24)$ and $2.1(\mathrm{SE}=0.49)$ spores recovered in gravity samplers over all distances and times per 1,000 source spores for C. acutatum-O and C. fragariae, respectively (Fig. 2).

Spore removal. Rain intensity and isolate also significantly affected spore removal from source fruits $(P<0.04)$. As expected, a slightly higher proportion of spores were removed from infected fruits over $16 \mathrm{~min}\left(S_{R}\right)$ at a rain intensity of $30 \mathrm{~mm} / \mathrm{h}$ than at $11 \mathrm{~mm} / \mathrm{h}$ (Table 1). There was no significant interaction between intensity and isolate $(P>0.10)$. Repetition (block) effect was not significant $(P>0.10)$. $S_{R}$ was higher for $C$. acutatum-O and $C$. gloeosporioides $(\approx 75 \%)$ than for the other isolates. $C$. fragariae had the lowest mean $S_{R}(\approx 33 \%)$, and C. acutatum-M had an intermediate mean.

The mean rate of spore removal $\left(\beta_{R}\right)$ followed trends similar to those for $S_{R}$. Removal rate was significantly affected by isolate and rain intensity $(P<0.022)$ but not by repetition $(P>0.10)$ (Table $1)$, and there was no significant interaction $(P>0.10)$. Mean $\beta_{R}$ was slightly higher for a rain intensity of $30 \mathrm{~mm} / \mathrm{h}$ than for $11 \mathrm{~mm} / \mathrm{h}$. Across the two rain intensities, $C$. acutatum-O and C. gloeosporioides had the highest mean values of $\beta_{R}$, and $C$. fragariae had the lowest.

Spore wash-off. The estimated proportion of spore wash-off from healthy fruits $\left(S_{W}\right)$ and rate of spore wash-off $\left(\beta_{W}\right)$ based on MIT of the proportion of infected fruits were significantly affected by rain intensity $(P<0.02)$ (Table 1$)$. More spores were washed-off by a rain intensity of $30 \mathrm{~mm} / \mathrm{h}$ than $11-\mathrm{mm} / \mathrm{h}$. Isolate did not significantly $(P>0.10)$ affect wash-off, and there was no significant interaction $(P>0.10)$. Across the two rain intensities, $\approx 40$ to $50 \%$ of spores were washed-off for all isolates, with rates $\beta_{W}$ between 0.04 and $0.06 / \mathrm{min}$.

Spore recovery from soil surface. Recovery of conidia uniformly sprayed over the entire soil surface was significantly affected by time of sampling during a rain $(P<0.001)$. Spore flux density declined over time (Table 2), as expected, because there was no influx of spores after initial application.

Isolate significantly affected spore flux density $(P<0.04)$, but there was no significant block effect $(P>0.05)$ or interaction between time and isolate $(P>0.50)$. Because of the lack of interaction, isolate comparisons could be made based on means across times. Mean $Y$ of the isolates was very similar (Table 2), and the only substantial (and significant) difference was between C. acutatum$\mathrm{O}$ and C. fragariae.

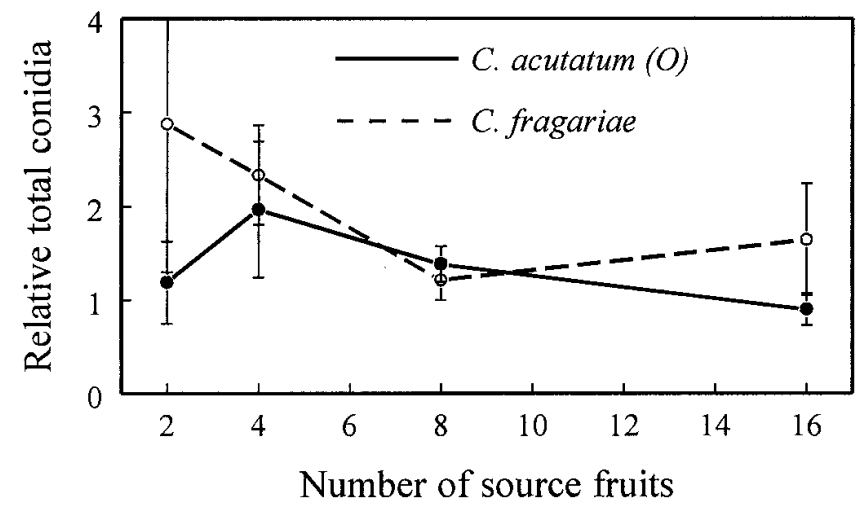

Fig. 2. Relative number of conidia (mean \pm standard error) of two Colletotrichum species collected on a selective medium from 2, 4, 8, and 16 fruits exposed to a rain intensity of $30 \mathrm{~mm} / \mathrm{h}$. Values represent 1,000 times the number of conidia over distance and time from the inoculum source divided by the number of spores at the source $\left(\Sigma_{r}\right)$.
Random-jump model. The splash-dispersal model generally gave satisfactory fits to the spore deposition data in Figure 1. Root meansquare errors for total spores dispersed at time $t\left(Y_{t}\right)$ ranged from 48 to 97 and, for mean-squared displacement distance $\left(\bar{r}_{t}^{2} \cdot Y_{0, r}\right)$, ranged from 2.2 to $9.8 \times 10^{4}$ (Table 3 ). Estimates of $\lambda$ and $\varepsilon$ increased with rain intensity for all isolates, and estimated $\sigma$ was not noticeably affected by rain intensity, as expected based on previous results (33) (Table 3).

C. acutatum-M was characterized by the lowest estimated $\varepsilon$ at both rain intensities and a generally low estimate of $\lambda$. However, there were few other consistent differences in parameter estimates among the isolates at the two rain intensities, indicating there was no clear evidence that the splash-dispersal process differed for the isolates tested.

\section{DISCUSSION}

Our results showed that conidia of the three Colletotrichum species infecting strawberry fruit (including two isolates of $C$. acutatum) were similarly, but not identically, dispersed by rain splash: deposition flux density of conidia $(Y)$ increased over time to a maximum during a simulated rain episode and then declined (Fig. 1). Additionally, deposition of conidia declined with distance from inoculum source, and few spores were found beyond $40 \mathrm{~cm}$. For all species, splash dispersal was affected by rain intensity. Higher rain intensity $(30 \mathrm{~mm} / \mathrm{h})$ resulted in greater splash dispersal than lower rain intensity $(11 \mathrm{~mm} / \mathrm{h})$, which was expected based on previous results (27,29). Differences between species and isolates did not depend on rain intensity, as indicated by the lack of interaction between isolate and rain intensity (Table 1).

$C$. fragariae had the slowest rate of conidial spore removal from the source (estimated $\beta_{R}$ ) and the lowest interpolated total number of conidia over time and distance $(\Sigma)$. C. acutatum-M had the next lowest removal rate. $C$. acutatum-O had the highest rate of spore removal and the largest $\Sigma$. However, interpolated total number of conidia collected in petri plates relative to initial spore density $\left(\Sigma_{r}\right)$ was similar for all isolates, except $C$. acutatum-M, which had the lowest mean $\Sigma_{r}$. The similarity of the species in other epidemiological characteristics, such as infection efficiency and sporulation rate, has been reported previously $(19,40)$.

Investigators have classified isolates of Colletotrichum species pathogenic to strawberries into three species based on morphological characteristics $(8,15,37)$, although there is a long history of argument over the taxonomy of the genus $(15-17,37)$. Setae production has been used as one specific characteristic to differentiate C. fragariae from C. gloeosporioides isolates, because both have

TABLE 2. Recovery of conidia of four Colletotrichum isolates uniformly dispersed on the soil surface based on colonies formed in petri plates containing selective media at 0,2 , and 4 min of splash dispersal at a rain intensity of $30 \mathrm{~mm} / \mathrm{h}^{\mathrm{x}}$

\begin{tabular}{lccccc}
\hline & \multicolumn{3}{c}{ Conidia $\left(\mathrm{cm}^{-2} \mathrm{~min}^{-1}\right)$ at time $(\mathrm{min})$} & Transformed \\
\cline { 2 - 5 } Isolate $^{\mathrm{y}}$ & 0 & 2 & 4 & Mean & mean $^{\mathrm{z}}$ \\
\hline C. acutatum-O & 42.2 & 26.8 & 14.8 & 27.9 & $1.92 \mathrm{a}$ \\
& $(4.89)$ & $(0.62)$ & $(0.55)$ & $(1.92)$ & \\
C. acutatum-M & 33.6 & 16.4 & 8.7 & 19.6 & $1.77 \mathrm{ab}$ \\
& $(0.13)$ & $(2.60)$ & $(1.17)$ & $(1.21)$ & \\
C. gloeosporioides & 35.5 & 19.9 & 8.4 & 21.3 & $1.78 \mathrm{ab}$ \\
& $(9.27)$ & $(6.58)$ & $(1.79)$ & $(5.64)$ & \\
C. fragariae & 24.0 & 14.2 & 5.9 & 14.8 & $1.66 \mathrm{~b}$ \\
& $(4.22)$ & $(0.63)$ & $(1.60)$ & $(2.08)$ & \\
Mean & 33.9 & 20.1 & 9.5 & 21.2 & \\
& $(3.41)$ & $(2.38)$ & $(1.23)$ & $(1.07)$ & \\
\hline
\end{tabular}

x Standard errors are given in parentheses.

y Isolate designations and origins are given in text.

${ }^{\mathrm{z}}$ Based on the fifth-root transformation of conidia numbers in each replication. Means followed by the same letter are not significantly different based on Fisher's protected LSD test $(P=0.05)$. 
similar spore shapes (16,37). C. acutatum isolates do not produce setae and also are separated from $C$. fragariae and $C$. gloeosporioides isolates by their slower radial growth rate on PDA at temperatures higher than $30^{\circ} \mathrm{C}$ (37). Molecular and isozyme research $(3,13,20,36)$ have confirmed the uniqueness of the three species. It is not surprising, therefore, that there was a high degree of similarity in splash-dispersal results shown here after corrections were made for differences in inoculum density on source fruits. Specifically, the estimated total number of conidia deposited over space and time, represented as a fraction of source strength $\left(\Sigma_{r}\right)$, was very similar for most of the tested isolates; only $C$. acutatum-M had a different relative number of dispersed spores (Table 1).

A fixed number of infected inoculum source fruits, rather than a fixed inoculum density at the point source, was used for the main dispersal experiment (Fig. 1), even though spore density per fruit was different among isolates. A fixed fruit number seemed appropriate, because a fruit is the natural unit in the field that becomes diseased and field disease spread is quantified in terms of the percentage of diseased fruits $(24,25)$. Moreover, before this study, we were uncertain what effect source strength would have on dispersal. For instance, Yang et al. (46) found no significant differences in dispersal of C. acutatum-O when one, five, or nine source fruits were used. However, they measured dispersal by the less precise variable of the proportion of fruits that became diseased after exposure to splashing rain. When dispersal was measured in absolute numbers of conidia deposited $(\Sigma)$, the results mostly were positively correlated with number of spores at the source (Table 1). Dividing $\Sigma$ by spore density at the source $\left(=\Sigma_{r}\right)$ produced very different results: the relative number of conidia was very similar for all isolates except $C$. acutatum-M. We should point out that the calculation of $\Sigma_{r}$ is based on the assumption that there is a linear relationship between source strength and number of spores dispersed, which is equivalent to no relationship between $\Sigma_{r}$ and number of spores at the source. This assumption was confirmed by the experiment involving number of inoculum source fruits and resulting $\Sigma_{r}$. Specifically, the lack of significant effect of number of fruit on $\Sigma_{r}$ (Fig. 2) revealed that one may be able to correct for source strength generally when quantifying splash dispersal.

Consideration of the components of splash dispersal of Colletotrichum species can expand our understanding of the observed pattern of spore deposition in space and time during rain episodes. Rate of spore removal from source fruits $\left(\beta_{R}\right)$ is, in part, a measure of the probability per unit of time that a spore will be splashed $(27,33)(\lambda$ in equation 1$)$ and is a function of rain intensity and properties of the surface and organism. However, this probability of splash may be different for a spore on the ground (after removal from the source) compared with a spore in a lesion. In agreement with past works $(27,30)$, removal rate increased with rain intensity, but this rate also was affected by isolate (Table 1). Mean removal rate was highest for $C$. acutatum-O and $C$. gloeosporioides and lowest for $C$. fragariae, with an intermediate value for C. acutatum-M. Because of the morphological similarities in the species $(15,17,37)$, we presume the differences in removal rate (or proportion of spores removed) were due to the properties of the mucilage matrix surrounding the spores (28). Further studies will need to focus on the amount and chemical properties of the mucilage produced by these species.

A strong relationship between the splash rate in the main experiment, based on the estimated $\lambda$ of equation 1 (Table 3 ), and the removal rate was not found, however. This could be due to the fact that $\lambda$ was not determined directly (i.e., not from measured splash of spores from single sites) but from curve-fitting of an overall complex process of spore deposition at a range of times and distances. Because the model did not provide a perfect fit to the data and the physical assumptions of equation 1 may be incomplete (e.g., a fixed splash rate for the entire area $[33,34]$ ), the exact physical meaning of the estimate of $\lambda$ in Table 1 is uncertain.

Prior comparative dispersal studies $(9,11,12,14,26,38,44)$ primarily emphasized the liberation of spores into splash droplets when lesions (or cultures) were impacted by single drops of water. Thus, these studies essentially dealt with the process we characterized here as removal. Clearly, studies with single drops allow one to determine the subcomponents of the removal process, such as number and size distribution of droplets per drop impact, number and distribution of spores in the droplets for each drop impact (18), and distribution of flight distances of droplets (summarized by $\sigma$ ). Gregory et al. (14) counted more than 3,000 droplets, ranging from 0.005 to $2.4 \mathrm{~mm}$ in diameter, when a 5 -mm drop diameter fell on a 0.1 -mm-deep spore suspension of Fusarium solani $\left(1.6 \times 10^{5}\right.$ spores per $\mathrm{ml}$ ). Approximately $47 \%$ of the droplets carried spores. Droplet size distribution was approximately lognormal. In experiments with Pseudocercosporella herpotrichoides and Pyrenopeziza brassicae (9), a 5-mm-diameter drop dispersed 90,000 spores from suspensions with $1.2 \times 10^{5}$ spores per ml. Fewer conidia, however, were dispersed from infected plant material. For instance, $\approx 25$ spores per splash were dispersed from wheat straw infected by Septoria nodorum, with $10^{7}$ spores per g dry weight, or Pseudocercosporella herpotrichoides, with $10^{4}$ spores per straw $(5,10)$. In another study, Yang et al. (44) found that when a single 4-mm-diameter drop impacted on an infected strawberry fruit (same condition as source fruits used here) $\approx 12,000$ conidia of $C$. acutatum were dispersed, in contrast to 56 sporangia of Phytophthora cactorum. Similar results were found by other investigators $(5,10)$. Although the measurement of spore removal in this study is less detailed than in the cited works, our approach allowed us to quantify the process per unit time when drops of various sizes impacted on an area $(27,30,35)$, which is the norm during natural rains.

TABLE 3. Estimated parameters and standard errors (in parentheses) of equation 1 and root mean-square errors for spore density at distance $r$ and time $t$ determined by jointly fitting equations ${ }^{\mathrm{x}}$ to the composite variables of number of spores over all distances at $t$ (Number) and mean-squared displacement distance of spores from the inoculum source times the number of spores at the source (Distance)

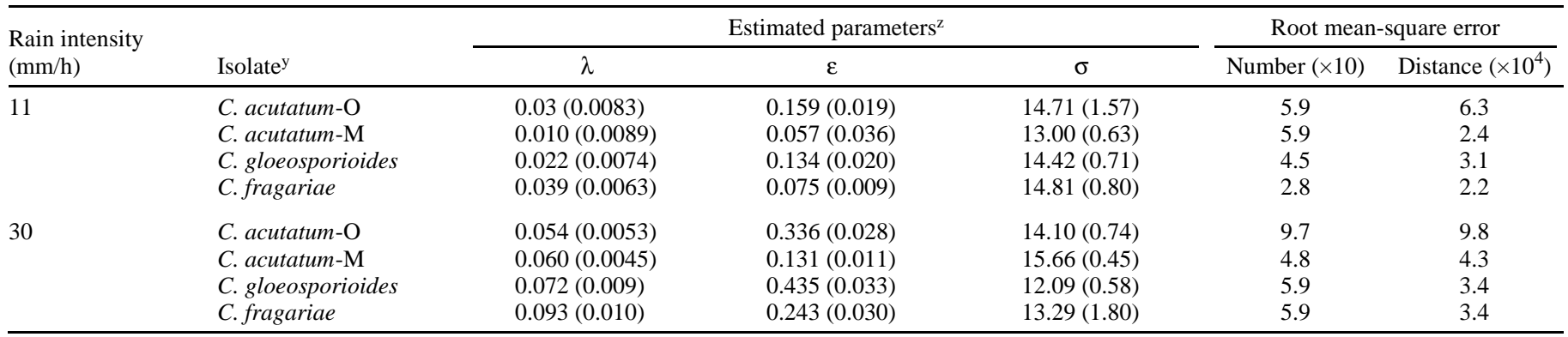

\footnotetext{
${ }^{x}$ Equations 15 and 21 in Pielaat et al. (33).

${ }^{y}$ Isolate designations and origins are given in text.

${ }^{\mathrm{z}}$ Parameter $\lambda$ : probability per time of a spore being splashed; $\varepsilon$ : probability per splash event of a spore remaining in the system $(1-\varepsilon$ is the probability per splash of a spore being removed [lost]); and $\sigma$ : standard deviation of the distribution of distances spores can travel during a single splash event. Standard errors are given in parentheses.
} 
A high rate of removal of spores from the inoculum source $\left(\beta_{R}\right)$ does not necessarily mean that total conidia $\left(\Sigma\right.$ or $\left.\Sigma_{r}\right)$ will be higher than for a situation with a lower rate. Obviously, increasing the removal rate results in more spores entering the system at a given time, but this provides more opportunities for spores to be removed from the system (e.g., through soil infiltration). As discussed by Pielaat et al. (33), there is a nonzero probability that a spore will be lost with every splash event; loss of spores is the reason why spore deposition flux density $(Y)$ decreases during longer time periods (Fig. 1). Of the various components of rain splash dispersal, spore loss may be the most difficult to determine by direct study of the process. In principle, however, the estimated loss rate per splash from equation $1(1-\varepsilon$; Table 3$)$ can be used to assess this attribute (33). Results from fitting the random-jump model to the data showed that the loss rate was larger for $C$. acutatum-M than for the other isolates, indicating that in each splash there was a somewhat greater probability that a $C$. acutatum-M spore would be removed compared with the other isolates. The large loss rate, together with the intermediate removal rate from the source, was a partial explanation for the lower relative total number of dispersed conidia of C. acutatum-M (Table 1).

When spores are removed from a source, they travel distances in splash droplets that depend on rain intensity and surface properties $(29,41,45,46)$. We did not directly measure flight distances for individual splash events, and we assumed there would not be differences among species or isolates in flight distances once spores were removed from the source. The $\sigma$ parameter of the random-jump model is a measure of the average distance of spore transport (equation 1), which in theory reflects the standard deviation of distances of the population of splash droplets containing spores. For the main experiment (Fig. 1), estimated $\sigma$ was not consistently affected by species or isolate (Table 3 ) and was marginally affected by rain intensity (also found by Pielaat et al. [33]). Thus, there was no evidence against our assumption of invariance of $\sigma$ for these closely related species.

Splashing of spores in the system after removal from the source could be assessed with the results of the two studies based on application of spore suspensions to fruits (wash-off) and soil (recovery). In terms of rate of spore wash-off from fruits $\left(\beta_{W}\right)$, the isolates were virtually identical (Table 1 ). Recovery of spores applied homogeneously on soil in splash droplets deposited in petri plates was only slightly affected by species or isolate (Table 2). The largest difference in spore flux density was between $C$. acutatum-O and $C$. fragariae (Table 2). The lower value for $C$. fragariae was consistent with the lower removal rate from source fruits $\left(\beta_{R}\right.$; Table 1). Therefore, although $C$. fragariae spores were not splashed from healthy fruits at a rate that differed from the other isolates, they were splashed at a somewhat lower rate in other parts of the system. Because spores are lost with every splash event (i.e., $\varepsilon<1$ ), a lower degree of splash from soil ensured that the smaller number of spores released into the system stayed in the system longer, resulting in the mean relative total number of dispersed conidia being approximately the same for $C$. fragariae as for the other tested isolates. Compared with the splash-dispersed differences found here, other studies have shown larger differences in several components of dispersal among less closely related fungi $(5,10,12,44)$.

In conclusion, closely related Colletotrichum species were splash dispersed in a similar manner under controlled conditions at two constant rain intensities. There were differences in some individual components of dispersal among species. However, the largest difference in overall dispersal, as quantified by relative total number of dispersed conidia $\left(\Sigma_{r}\right)$, was between the two isolates of $C$. $a c u$ tatum, which indicates that the intraspecies variation in splash dispersal could be as great as the interspecies variation, and one must use caution in generalizing about the magnitude of splash dispersal of a species based on results from a single isolate. Nevertheless, the difference between the two isolates of $C$. acutatum was quantitative; these isolates, as well as the tested isolates of the other two species, were in qualitative agreement.

\section{ACKNOWLEDGMENTS}

Research support and salaries provided by state and federal funds (especially USDA-NRI Competitive Grant 95-37303-1788) appropriated to the Ohio Agricultural Research and Development Center, The Ohio State University, Wooster. We thank B. J. Smith, U.S. Department of Agriculture, Agriculture Research Service, Poplarville, MS, for providing some isolates used in this study.

\section{LITERATURE CITED}

1. Allen, R. C. 1988. The mechanics of splashing. J. Colloid Interface Sci. 124:309-316.

2. Beraha, L., and Wright, W. R. 1973. A new anthracnose of strawberry by Colletotrichum dermatium. Plant Dis. Rep. 57:445-448.

3. Bonde, M. R., Peterson, G. L., and Maas, J. L. 1991. Isozyme comparisons for identification of Colletotrichum species pathogenic to strawberry. Phytopathology 81:1523-1528.

4. Boudreau, M. A., and Madden, L. V. 1995. Effect of strawberry density on dispersal of Colletotrichum acutatum by simulated rain. Phytopathology 85:934-941.

5. Brennan, R. M., Fitt, B. D. L., Taylor, G. C., and Colhoun, J. 1985. Dispersal of Septoria nodorum pycnidiospores by simulated raindrops in still air. Phytopathol. Z. 112:281-290.

6. Campbell, C. L., and Madden, L. V. 1990. Introduction to Plant Disease Epidemiology. John Wiley \& Sons, Inc., New York.

7. Eastburn, D. M., and Gubler, W. D. 1990. Strawberry anthracnose: Detection and survival of Colletotrichum acutatum in soil. Plant Dis. 74:161163.

8. Farr, D. F., Bills, G. F., Chamuris, G. P., and Rossman, A. Y. 1989. Fungi on Plants and Plant Products in the United States. The American Phytopathological Society, St. Paul, MN.

9. Fatemi, F., and Fitt, B. D. L. 1983. Dispersal of Pseudocercosporella herpotrichoides and Pyrenopeziza brassicae spores in splash droplets. Plant Pathol. 32:401-404.

10. Fitt, B. D. L., and Lysandrou, M. 1984. Studies on mechanisms of splash dispersal of spores, using Pseudocercosporella herpotrichoides spores. Phytopathol. Z. 111:323-331.

11. Fitt, B. D. L., and McCartney, H. A. 1986. Spore dispersal in splash droplets. Pages 87-104 in: Water, Fungi and Plants. P. G. Ayres and L. Boddy, eds. Cambridge University Press, Cambridge.

12. Fitt, B. D. L., McCartney, H. A., and Walklate, P. J. 1989. The role of rain in dispersal of pathogen inoculum. Annu. Rev. Phytopathol. 27:241-270.

13. Freeman, S., Pham, M., and Rodriguez, R. J. 1993. Molecular genotyping of Colletotrichum species based on arbitrarily primed PCR, A+T-rich DNA, and nuclear DNA analyses. Exp. Mycol. 17:309-322.

14. Gregory, P. H., Guthrie, E. J., and Bunce, M. E. 1959. Experiments on splash dispersal of fungus spores. J. Gen. Microbiol. 20:328-354.

15. Gunnell, P. S., and Gubler, W. D. 1992. Taxonomy and morphology of Colletotrichum species pathogenic to strawberry. Mycologia 84:157-165.

16. Howard, C. M., and Albregts, E. E. 1983. Black leaf spot phase of strawberry anthracnose caused by Colletotrichum gloeosporioides $(=C$. fragariae $)$. Plant Dis. 67:1144-1146.

17. Howard, C. M., Mass, J. L., Chandler, C. K., and Albregts, E. E. 1992. Anthracnose of strawberry caused by the Colletotrichum complex in Florida. Plant Dis. 76:976-981.

18. Huber, L., Fitt, B. D. L., and McCartney, H. A. 1996. The incorporation of pathogen spores into rain-splash droplets: A modeling approach. Plant Pathol. 45:506-517.

19. King, W. T., Madden, L. V., Ellis, M. A., and Wilson, L. L. 1997. Effects of temperature on sporulation and latent period of Colletotrichum spp. infecting strawberry fruit. Plant Dis. 81:77-84.

20. Lenné, J. M., and Burdon, J. J. 1990. Preliminary study of virulence and isozyme variation in natural populations of Colletotrichum gloeosporioides from Stylosanthes guianensis. Phytopathology 80:728-731.

21. MacDonald, O. C., and McCartney, H. A. 1987. Calculation of splash droplet trajectories. Agric. For. Meteorol. 39:95-110.

22. Madden, L. V. 1992. Rainfall and the dispersal of fungal spores. Adv. Plant Pathol. 8:39-79.

23. Madden, L. V. 1993. Aggregation of Colletotrichum acutatum in response to simulated rain episodes. J. Phytopathol. 138:145-156.

24. Madden, L. V., and Boudreau, M. A. 1997. Effect of strawberry density on the spread of anthracnose caused by Colletotrichum acutatum. Phytopathology 87:828-838.

25. Madden, L. V., Wilson, L. L., and Ellis, M. A. 1993. Field spread of anthracnose fruit rot of strawberry in relation to ground cover and ambient weather conditions. Plant Dis. 77:861-866.

26. Madden, L. V., Wilson, L. L., Yang, X., and Ellis, M. A. 1992. Splash dispersal of Colletotrichum acutatum and Phytophthora cactorum by 
short-duration simulated rains. Plant Pathol. 41:427-436.

27. Madden, L. V., Yang, X., and Wilson, L. L. 1996. Effects of rain intensity on splash dispersal of Colletotrichum acutatum. Phytopathology 86:864-874.

28. Nicholson, R. L., Hipskind, J., and Hanau, R. M. 1989. Protection against phenol toxicity by the spore mucilage of Colletotrichum graminicola, an aid to secondary spread. Physiol. Mol. Plant Pathol. 35:243-252.

29. Ntahimpera, N., Ellis, M. A., Wilson, L. L., and Madden, L. V. 1998. Effects of a cover crop on splash dispersal of Colletotrichum acutatum conidia. Phytopathology 88:536-543.

30. Ntahimpera, N., Madden, L. V., and Wilson, L. L. 1997. Effect of rain distribution alteration on the splash dispersal of Colletotrichum acutatum. Phytopathology 87:649-655.

31. Ntahimpera, N., Wilson, L. L., and Madden, L. V. 1997. Comparison of rain effects on splash dispersal of three Colletotrichum species. (Abstr.) Phytopathology 87 (Suppl.):S71.

32. Papavizas, G. C., and Davey, C. B. 1959. Evaluation of various media and antimicrobial agents for isolation of soil fungi. Soil Sci. 88:112-117.

33. Pielaat, A., Gort, G., and Madden, L. V. 1997. Spores splashing under different environmental conditions: A modeling approach. Phytopathology 88:1131-1140.

34. Pielaat, A., and van den Bosch, F. 1998. A model for dispersal of plant pathogens by rain splash. IMA. J. Math. Appl. Med. Biol. 15:117-134.

35. Reynolds, K. M., Bulger, M. A., Madden, L. V., and Ellis, M. A. 1987. New methods using simulated rains to study the splash dispersal of plant pathogens. Phytopathology 77:921-926.

36. Sreenivasaprasad, S., Brown, A. E., and Mills, P. R. 1992. DNA sequence variation and interrelationships among Colletotrichum species causing strawberry anthracnose. Physiol. Mol. Plant Pathol. 41:265-281.

37. Smith, B. J., and Black, L. L. 1990. Morphological, cultural, and patho- genic variation among Colletotrichum species isolated from strawberry. Plant Dis. 74:69-76.

38. Stepanov, K. M. 1935. Dissemination of infective diseases of plants by air currents (Ru.). Bull. Plant Prot. Leningrad Ser. 2 Phytopathol. 8:1-68.

39. Wilson, L. L., Madden, L. V., and Ellis, M. A. 1990. Influence of temperature and wetness duration on infection of immature and mature straberry fruit by Colletotrichum acutatum. Phytopathology 80:111-116.

40. Wilson, L. L., Madden, L. V., and Ellis, M. A. 1994. Effect of temperture on strawberry fruit infection by geographic isolates of three Collettrichum species. (Abstr.) Phytopathology 84:1071.

41. Yang, X., and Madden, L. V. 1993. Effect of ground cover, rain intensity, and strawberry plants on splash of simulated raindrops. Agric. For. Meteorol. 65:1-20.

42. Yang, X., Madden, L. V., and Brazee, R. D. 1991. Application of the diffusion equation for modeling splash dispersal of point source pathogens. New Phytol. 118:295-301.

43. Yang, X., Madden, L. V., Reichard, D. L., Fox, R. D., and Ellis, M. A. 1991. Motion analysis of drop impaction on a strawberry surface. Agric. For. Meteorol. 56:67-92.

44. Yang, X., Madden, L. V., Reichard, D. L., Wilson, L. L., and Ellis, M. A. 1992. Splash dispersal of Colletotrichum acutatum and Phytophthora cactorum from strawberry fruit by single drop impactions. Phytopathology 82:332-340.

45. Yang, X., Madden, L. V., Wilson, L. L., and Ellis, M. A. 1990. Effects of surface topography and rain intensity on splash dispersal of Colletotrichum acutatum. Phytopathology 80:1115-1120.

46. Yang, X., Wilson, L. L., Madden, L. V., and Ellis, M. A. 1990. Rain splash dispersal of Colletotrichum acutatum from infected strawberry fruit. Phytopathology 80:590-595. 